\title{
Allogeneic Red Blood Cell Transfusion Rate and Risk Factors in Elderly Patients With Femoral Neck Fracture After Hemiarthroplasty
}

Rui Yue

Beijing Jishuitan Hospital

Minghui Yang

Beijing Jishuitan Hospital

\section{Xiaohui Deng}

Beijing Jishuitan Hospital

Ping Zhang ( $\nabla$ zhangping_cn@126.com)

Department of Cadre Health Care, Beijing Jishuitan Hospital, No. 31 of Xinjiekou East Street, Xicheng District, Beijing 100035, China

\section{Research article}

Keywords: femoral neck fracture, hemiarthroplasty, risk factors, old age, allogeneic red blood cell transfusion

Posted Date: October 7th, 2020

DOI: https://doi.org/10.21203/rs.3.rs-84458/v1

License: @ (i) This work is licensed under a Creative Commons Attribution 4.0 International License. Read Full License

Version of Record: A version of this preprint was published at Frontiers in Physiology on July 29th, 2021. See the published version at https://doi.org/10.3389/fphys.2021.701467. 


\section{Abstract}

Objective: To determine the rate and risk factors of allogeneic red blood cell transfusions (ABT) in elderly patients with femoral neck fracture (FNF) after hemiarthroplasty (HA).

Methods: We conducted a study on elderly patients ( $\geq 65$ years old) who were admitted to the geriatric trauma orthopedics ward of Beijing Jishuitan Hospital for HA treatment from March 2018 to February 2019 due to FNF. The perioperative data were collected retrospectively, and univariate and multivariate stepwise logistic regression analysis were performed to determine the postoperative $A B T$ rate and its risk factors.

Results: 343 patients were included in the study, of which 151 (44.0\%) received ABT after surgery. Multivariate stepwise logistic regression analysis showed that preoperative low hemoglobin $(\mathrm{Hb})$, high intraoperative blood loss (IBL), advanced age, and low body mass index (BMI) are independent risk factors of ABT after HA in elderly FNF patients.

Conclusion: ABT after HA is a common phenomenon in elderly patients with FNF. Their postoperative ABT needs are related to preoperative low Hb, high IBL, advanced age, and low BMI. Therefore, ABT can be reduced from the above aspects.

\section{Introduction}

Hip fractures are an important reason for the hospitalization of elderly people. Millions of elderly patients worldwide suffer from hip fractures due to minor violence each year ${ }^{[1]}$. Compared with other types of fractures, the incidence of hip fractures in the elderly is high, the mortality rate is high, and the patients are prone to loss of independence ${ }^{\text {[2] }}$. The current treatment methods include conservative treatment and surgery. Surgical treatment can reduce bed time, get patients out of bed as soon as possible, and reduce bed-ridden complications. It has been adopted by most physicians. FNF is one of the types of hip fractures. HA is currently a recognized method for the treatment of FNF. It is suitable for elderly displaced FNF with low functional requirements and no acetabular wear ${ }^{[3]}$. Compared with total hip arthroplasty, FNF patients treated with HA have shorter operative time, less IBL, lower incidence of postoperative dislocation, shorter hospital stay, and lower cost ${ }^{[3,4]}$. Nevertheless, it still has many short-term and long-term shortcomings, such as: ABT, groin pain caused by acetabular wear and the potential risk of requiring revision surgery ${ }^{[3,4]}$. Among them, $A B T$ is the most common, especially for the elderly. $A B T$ has many serious adverse reactions ${ }^{[5,6]}$, including: acute hemolytic transfusion reaction, blood-borne infections (such as human immunodeficiency virus, hepatitis), prolonged hospital stay, increasing blood resource tension and patient medical burden. Because the elderly have poor tolerance to blood transfusion, blood transfusion-related complications are more likely to occur. Although there are reports in the literature on the risk factors of blood transfusion after hip fracture, we know that the amount of blood loss caused by FNF and intertrochanteric fractures is different. The choice of different surgical procedures for the same type of fracture will also affect the amount of blood loss, which in turn affects the postoperative blood transfusion rate. At present, there are few research reports on ABT after HA in elderly FNF patients. Therefore, this study will take these patients as the research object to study the predictors of $A B T$ in elderly FNF patients after $H A$, in order to help clinicians identify high-risk patients, carry out early intervention, and reduce the rate of postoperative ABT.

\section{Materials And Methods}

\subsection{Patients}

Inclusion criteria: $₫ A g e \geq 65$ years old, $\triangle F N F$ caused by low-energy injury (such as standing height fall, osteoporosis, etc.), $\nabla H A$ for $\mathrm{FNF}, \mathbb{\nabla N o}$ history of bleeding diseases such as bone tumors, chronic liver diseases, and blood system diseases. Exclusion criteria: 囚open soft tissue fractures, \multiple fractures, 『pathological fractures. We selected patients who were admitted to the elderly trauma orthopedics ward of our hospital from March 2018 to February 2019 due to hip fractures, and finally included 343 patients who met the selection criteria. All patients received standard HA treatment in our hospital. Based on the policy of restricted blood transfusion, we only transfuse red blood cells to patients with $\mathrm{Hb}$ lower than $80 \mathrm{~g} / \mathrm{L}$ or $\mathrm{Hb}$ lower than $100 \mathrm{~g} / \mathrm{L}$, but with unstable vital signs or obvious symptoms (heart rate $>100$ beats / min, systolic blood pressure $<90 \mathrm{mmHg}$, chest pain, 
massive bleeding or extreme weakness). All patients were treated with low molecular weight heparin anticoagulation during the perioperative period, and tranexamic acid was used during the operation. This study was approved by the Ethics Committee of Beijing Jishuitan Hospital, with the ethics approval number: Ji Lun Ke Shen Zi No. 201807-11. All participants signed informed consent.

\subsection{Potential risk factors}

The risk factors evaluated include the patient's gender, age, BMI, comorbid diseases (such as hypertension, diabetes, coronary atherosclerotic heart disease, cerebrovascular disease, chronic lung disease), whether to take antiplatelet drugs (aspirin and / or clopidogrel), $\mathrm{Hb}$ before surgery, time from fracture to surgery, type of anesthesia (general anesthesia or intraspinal anesthesia), American Association of Anesthesiologists (ASA) classification, IBL, and duration of surgery.

\subsection{Statistical analysis}

Statistical analysis was performed using SPSS 22.0. Quantitative data that obey the normal distribution are expressed as mean \pm standard deviation $\mathbb{} \times \pm \mathrm{s} \otimes$, and independent sample $t$ test is used for comparison between groups; quantitative data that do not follow a normal distribution are represented by the median (interquartile range) [M(P25, P75)], and the rank sum test is used for comparison between groups; the qualitative data is expressed by frequency and percentage, and the $₫ 2$ test is used for comparison between groups. Single factor analysis was used to evaluate the relationship between different factors and ABT. Then multi-factor stepwise logistic regression was used to control the confounding effect. Continue to exclude predictors until the $\mathrm{p}$ values of all predictors are less than 0.05 .

\section{Results}

The study included 343 patients, aged $65-98$ years, with an average age of $(81.9 \pm 6.8)$ years. Among all patients, 105 were males (30.6\%) and 238 were females (69.4\%).

The univariate analysis in Table 1 showed that there was no statistical difference between the two groups in gender, comorbid diseases except diabetes, ASA grade, anesthesia, time from fracture to surgery, duration of surgery, and whether antiplatelet drugs were taken 1 week before surgery. The preoperative $\mathrm{Hb}$ and BMI of the blood transfusion group were significantly lower than those of the non-transfusion group, and the IBL and age were significantly higher than those of the non-transfusion group.

Multivariate stepwise logistic regression analysis showed that low preoperative $\mathrm{Hb}$, high IBL, advanced age, and low $\mathrm{BMI}$ were independent risk factors for ABT after HA in elderly FNF patients. Among them, the Wald value of preoperative $\mathrm{Hb}$ was the largest, indicating that low $\mathrm{Hb}$ before surgery has the greatest impact on ABT after surgery (Table 2).

\section{Discussion}

Regarding the blood transfusion rate after hip fracture surgery, there have been different reports in domestic and foreign literature. This may be related to the age, fracture type, comorbid diseases, blood transfusion policy, etc. of the subjects in each study. Arshi A et al. ${ }^{[7]}$ studied 8416 elderly hip fracture patients over 65 years of age and found that $28.3 \%$ of them were transfused after surgery. Many previous studies have concluded that compared with FNF, the risk of blood transfusion after femoral intertrochanter fracture is increased ${ }^{[7,8]}$. This study did not include patients with femoral intertrochanteric fractures, but the postoperative ABT was even higher. It may be because our hospital is a large-scale upper first-class general hospital with orthopedics and burns as the key department. Part of the patients admitted were referred from primary hospitals. The patients were older, had many complicated diseases, and had relatively severe illness, which also resulted in the relatively high postoperative ABT rate in this study. In the study of Wang JQ et al. ${ }^{[9]}$, the elderly patients with HA after FNF were also taken as the research objects, but they found that the postoperative blood transfusion rate was only $13.9 \%$, which was significantly lower than the $44.0 \%$ in this study. Then what are the reasons? In the study of Wang JQ et al. ${ }^{[9]}$, the average age of the blood transfusion group was $(78.95 \pm 5.26)$ years old, the non-transfusion group was $(80.82 \pm 5.23)$ years old, while in this study, the 
blood transfusion group was $(83.4 \pm 7.0)$ years old, and the non-transfusion group was $(80.8 \pm 6.5)$. It can be seen that the patients in this study are older, and advanced age itself is one of the risk factors for postoperative ABT.

At present, there is no clear regulation on the standard of blood transfusion for elderly patients with hip fracture ${ }^{\text {[10] }}$. Carson $\mathrm{JL}$ et al. ${ }^{[11]}$ systematically reviewed the results of 31 studies (including 12587 patients) and suggested that the restrictive blood transfusion strategy of controlling the blood transfusion standard at $\mathrm{Hb} 7-8 \mathrm{~g} / \mathrm{dL}$ can reduce the ABT rate by $43 \%$. It will not increase the mortality, complication rate and readmission rate within 30 days after surgery, nor will it affect the recovery of patients after surgery. The research of Xie Xuhong et al. ${ }^{[12]}$ shows that for elderly patients undergoing surgical treatment of hip fractures, restricted blood transfusion is safe and effective, and it does not affect the prognosis of patients, and is significantly better than unrestricted blood transfusion in terms of adverse reactions after blood transfusion and blood saving. Based on the above reasons, this study adopted a restrictive blood transfusion strategy.

Multivariate stepwise logistic regression analysis showed that low preoperative $\mathrm{Hb}$, high IBL, advanced age, and low BMI were independent risk factors for ABT in elderly FNF patients after HA. In this study, the preoperative $\mathrm{Hb}$ of the blood transfusion group was $(113.9 \pm 14.0) \mathrm{g} / \mathrm{L}$, which was significantly lower than the preoperative $\mathrm{Hb}(128.2 \pm 12.8) \mathrm{g} / \mathrm{L}$ of the non-transfusion group $(p<0.05)$. This result is consistent with many previous studies ${ }^{[7,9,13]}$. Adunsky $A$ et al. ${ }^{[14]}$ found that patients with preoperative $\mathrm{Hb}$ lower than $120 \mathrm{~g} / \mathrm{L}$ have a 5 -fold increase in the risk of postoperative blood transfusion. It is speculated that the reason may be due to the poor immune response and compensatory ability of patients with low $\mathrm{Hb}$ before surgery when faced with stresses such as surgery and blood loss. Shokoohi A et al. ${ }^{[15]}$ further reported that for every $1 \mathrm{~g} / \mathrm{dl}$ increase in Hb on admission, the chance of a patient's blood transfusion decreased by about $49 \%$.

There are many reasons for preoperative anemia ${ }^{[6]} \rrbracket$ Acute and chronic hemorrhagic anemia: acute hemorrhagic anemia caused by fractures; chronic hemorrhagic anemia caused by bleeding from digestive ulcers, intestinal polyps or hemorrhoids. \Nutritional anemia: anemia caused by lack of hematopoietic materials, and iron deficiency anemia is the most common, and megaloblastic anemia caused by lack of folic acid and vitamin $B$ is rare. $₫$ Anemia of chronic disease: refers to anemia characterized by disorders of iron metabolism that occurs in the course of some chronic diseases, and is common in anemia combined with chronic infection, inflammation, and tumor. \Other anemia: it may involve a variety of complex pathogenic mechanisms and comorbidities. The elderly are more likely to have preoperative anemia due to multiple diseases, reduced absorption and utilization of hematopoietic materials, and reduced hematopoietic reserves. Yoon $\mathrm{BH}$ et al. ${ }^{[16]}$ believed that intravenous iron supplementation with restrictive blood transfusion is safe and effective for elderly patients with hip fractures.

We also found that IBL is an independent risk factor for ABT. The IBL of the transfusion group was $(231.8 \pm 97.0) \mathrm{ml}$, which was significantly higher than that of the non-transfusion group $(190.5 \pm 89.9) \mathrm{ml}(\mathrm{p}<0.05)$. It is consistent with the results of Wang $\mathrm{JQ}$ et al. ${ }^{[9]}$. Under normal circumstances, the amount of intraoperative blood loss increases the risk of blood transfusion. Xie $\mathrm{J}$ et al. ${ }^{[17]}$ believed that intraoperative use of tranexamic acid can reduce intraoperative bleeding, reduce postoperative $A B T$, and will not increase the risk of postoperative thromboembolic events or other adverse events. Tranexamic acid was used in all patients in this study.

Consistent with previous studies ${ }^{[7,13]}$, we found that advanced age is an independent risk factor for ABT in elderly FNF patients after $\mathrm{HA}$. This may be related to the lower baseline $\mathrm{Hb}$ of older people. In addition, elderly patients are more likely to experience unstable vital signs and acute blood loss related symptoms after surgery due to reduced organ function and weak compensatory ability to surgical stress, thus increasing the demand for ABT.

Our research shows that a lower BMI is a risk factor for postoperative ABT, similar to previous experimental results ${ }^{[7,18,19]}$. Frisch $\mathrm{N}$ et al. ${ }^{[18]}$ studied more than 2300 patients and found that after total hip and knee replacement, patients with high BMI had a lower blood transfusion rate. The author believes that the protective effect of BMI on the risk of blood transfusion may be related to the increase in overall blood volume with the increase of BMI. Although obese patients may lose more blood due to larger incisions during surgery, compared with patients with lower BMI, their estimated blood loss during a particular surgery 
may have a lower proportion of total blood volume ${ }^{[18]}$. In addition, lower BMI may also be an indicator of malnutrition in the elderly.

Different from the study of Yan Ge et al. ${ }^{[13]}$, in our study, whether antiplatelet drugs were taken 1 week before surgery did not affect ABT in FNF patients after HA. The experiment of Abdulhamid AK ${ }^{[20]}$ included 325 FNF patients, of which 163 had longterm use of antiplatelet drugs and $162 \mathrm{had}$ not used antiplatelet drugs. It was found that there was no statistical difference between the two groups in terms of IBL or postoperative blood transfusion requirements. In this experiment, many elderly patients with cardiovascular and cerebrovascular diseases have a high risk of stopping antiplatelet drugs, so antiplatelet drugs were not stopped during the perioperative period.

\section{Conclusion}

Blood transfusion increases the incidence of complications and leads to blood shortage, prolonged hospital stay and increased hospital costs. For elderly FNF patients undergoing HA, these problems cannot be ignored. In addition, for elderly patients with potential risk factors, it is necessary to improve blood management. It is currently believed that through risk assessment, careful surgical planning and optimization of preoperative evaluation, the need for blood transfusions during the perioperative period of elderly patients undergoing major surgery can be reduced ${ }^{[21]}$.

This study has several limitations: First, this study is based on retrospective data, and the sample size is relatively small, which will inevitably be affected by inherent data; second, all data in this study come from a hospital. Therefore, it is necessary to conduct a prospective multicenter study to validate our results.

\section{List Of Abbreviations}

ABT: allogeneic red blood cell transfusions

FNF: femoral neck fracture

HA: hemiarthroplasty

$\mathrm{Hb}$ : hemoglobin

IBL: intraoperative blood loss

BMI: body mass index

ASA: American Association of Anesthesiologists

\section{Declarations}

\section{Ethical statement}

This study was approved by the ethics committee of the Beijing Jishuitan Hospital(ethical batch number $\ 201807-11$ ), and informed consent was obtained from all participants.

\section{Consent for publication}

All authors final approval of the version to be published.

\section{Availability of data and materials}

The datasets used and/or analyzed during the current study are available from the corresponding author on reasonable request. 
All of the authors had no any personal, financial, commercial, or academic conflicts of interest separately.

\section{Authors Contribution}

Conception and design of the research: Yue R. Acquisition of data: Yue R, Yang MH. Analysis and interpretation of the data: Yue R, Zhang P. Statistical analysis: Zhang P. Obtaining financing : None. Writing of the manuscript : Yue R, Deng XH, Yang MH and Zhang P. Critical revision of the manuscript for intellectual content : Yue R.

\section{Acknowledgement}

None.

\section{Role of funding source:}

Capital's Funds for Health Improvement and Research (2018-1-2071)

\section{References}

[1] Mitchell MD, Betesh JS, Ahn J, Hume EL, Mehta S, Umscheid CA. Transfusion Thresholds for Major Orthopedic Surgery: A Systematic Review and Meta-analysis. J Arthroplasty, 2017, 32(12): 3815-3821.

[2] Kulshrestha V, Sood M, Kumar S, Sharma P, Yadav YK. Outcomes of Fast-Track Multidisciplinary Care of Hip Fractures in Veterans: A Geriatric Hip Fracture Program Report. Clin Orthop Surg, 2019, 11(4): 388-395.

[3] Grosso MG, Danoff JR, Padgett DE, lorio R, Macaulay WB. The Cemented Unipolar Prosthesis for the Management of Displaced Femoral Neck Fractures in the Dependent Osteopenic Elderly. J Arthroplasty, 2016, 31(5): 1040-1046.

[4] Liodakis E, Antoniou J, Zukor DJ, Huk OL, Epure LM, Bergeron SG. Major complications and transfusion rates after hemiarthroplasty and total hip arthroplasty for femoral neck fractures. J Arthroplasty, 2016, 31(9): 2008-2012.

[5] Smeets SJM, Verbruggen JPAM, Poeze M. Effect of blood transfusion on survival after hip fracture surgery. Eur J Orthop Surg Traumatol, 2018, 28: 1297-1303.

[6] Zhou ZK, Weng XS, Sun TS, Tang PF, Shen JX, Song YM, et al. Chinese orthopedic surgery accelerates recovery-Expert consensus on perioperative blood management [J]Chinese Journal of bone and joint surgery, 2017, 10(1): 1-7.

[7] Arshi A, Lai WC, Iglesias BC, McPherson EJ, Zeegen EN, Stavrakis Al, et al. Blood transfusion rates and predictors following geriatric hip fracture surgery. Hip Int, 2020, 1120700019897878.

[8] Martinsen MI, Valland H, Solheim LF, Holvik K, Ranhoff A. A restrictive policy for red blood cell transfusion in older hip fracture patients: experiences from a patient register. BMC Res Notes, 2016, 9: 75.

[9] Wang JQ, Chen LY, Jiang BJ, Zhao YM. Development of a Nomogram for Predicting Blood Transfusion Risk After Hemiarthroplasty for Femoral Neck Fractures in Elderly Patients. Med Sci Monit, 2020, 26: e920255.

[10] Zhu C, Yin J, Wang B, Xue QM, Gao S, Xing LY, et al. Restrictive versus liberal strategy for red blood-cell transfusion in hip fracture patients: A systematic review and meta-analysis. Medicine (Baltimore), 2019, 98(32): e16795.

[11] Carson JL, Stanworth SJ, Roubinian N, Fergusson DA, Triulzi D, Doree C, et al. Transfusion thresholds and other strategies for guiding allogeneic red blood cell transfusion®Cochrane Database Syst Rev, 2016, 10: CD002042

[12] Xie XH, Yan ZQ, Zhang DW, Wei YM. Comparative study on the curative effect of limited blood transfusion and open blood transfusion in perioperative period of elderly hip fracture [J]Chinese Journal of blood transfusion, 2019, 32 (07): 654-657 
[13] Yan G, Zhang P, Wang YS, Xu YQ. Regression analysis of influencing factors of postoperative blood transfusion in elderly patients with hip fracture [J] Medical clinical research, 2015, 32: 1085-1088.

[14] Adunsky A, Lichtenstein A, Mizrahi E, Arad M, Heim M. Blood transfusion requirements in elderly hip fracture patients. Arch Gerontol Geriatr 36: 75-81.

[15] Shokoohi A, Stanworth S, Mistry D, Lamb S, Staves J, Murphy MF. The risks of red cell transfusion for hip fracture surgery in the elderly. Vox Sang 2012, 103: 223-230.

[16] Yoon BH, Lee BS, Won H, Kim HK, Lee YK, Koo KH. Preoperative Iron Supplementation and Restrictive Transfusion Strategy in Hip Fracture Surgery. Clin Orthop Surg, 2019, 11(3): 265-269.

[17] Xie JW, Hu QS, Huang Q, Chen G, Zhou ZK, Pei FX. Efficacy and safety of tranexamic acid in geriatric hip fracture with hemiarthroplasty: a retrospective cohort study. BMC Musculoskelet Disord, 2019, 20(1): 304.

[18] Frisch N, Wessell NM, Charters M, Peterson Ed, Cann B, Greenstein A, et al. Effect of body mass index on blood transfusion in total hip and knee arthroplasty. Orthopedics. 2016, 39: e844-e849.

[19] Akinleye SD, Garofolo G, Culbertson MD, Homel P, Erez O. The Role of BMI in Hip Fracture Surgery. Geriatr Orthop Surg Rehabil, 2018, 9: 2151458517747414.

[20] Abdulhamid AK. Evaluation of the use of anti-platelet therapy throughout the peri-operative period in patients with femoral neck fracture surgery. A retrospective cohort study. Int Orthop. 2020, 10.1007/s00264-020-04633-7.

[21] Clevenger B, Mallett SV, Klein AA, Richards T. Patient blood management to reduce surgical risk. Br J Surg, 2015, 102(11):1325-1324.

\section{Tables}

Table 1. Univariate analysis of ABT after HA in elderly patients with FNF 


\begin{tabular}{|c|c|c|c|c|}
\hline Variable & $\begin{array}{l}\text { Non transfusion } \\
\text { group }\end{array}$ & $\begin{array}{l}\text { Blood transfusion } \\
\text { group }\end{array}$ & $\begin{array}{l}\mathrm{t} / Z / \chi^{2} \\
\text { Value }\end{array}$ & $\begin{array}{l}\mathrm{P} \\
\text { Value }\end{array}$ \\
\hline Number of patients & 192 & 151 & & \\
\hline Gender & & & 0.994 & 0.319 \\
\hline Male & 63 & 42 & & \\
\hline Female & 129 & 109 & & \\
\hline Age $\bigotimes$ Year》 & $80.8 \pm 6.5$ & $83.4 \pm 7.0$ & 3.647 & $0.000 *$ \\
\hline $\mathrm{BM} \| \mathrm{kg} / \mathrm{m}^{2} \square$ & $22.6 \pm 3.7$ & $21.1 \pm 4.0$ & -3.644 & $0.000 *$ \\
\hline $\begin{array}{l}\text { Whether to take antiplatelet drugs one week before } \\
\text { surgery }\end{array}$ & & & 0.001 & 0.980 \\
\hline yes & 46 & 36 & & \\
\hline no & 146 & 115 & & \\
\hline hypertension & & & 1.587 & 0.208 \\
\hline yes & 116 & 81 & & \\
\hline no & 76 & 70 & & \\
\hline diabetes & & & 8.280 & $0.004 *$ \\
\hline yes & 68 & 32 & & \\
\hline no & 124 & 119 & & \\
\hline Atherosclerotic heart disease & & & 0.518 & 0.472 \\
\hline yes & 55 & 38 & & \\
\hline no & 137 & 113 & & \\
\hline Cerebrovascular disease & & & 3.037 & 0.081 \\
\hline yes & 65 & 38 & & \\
\hline no & 127 & 113 & & \\
\hline Chronic lung disease & & & 0.062 & 0.803 \\
\hline yes & 20 & 17 & & \\
\hline no & 172 & 134 & & \\
\hline PreoperativeHb囚g/L】 & $128.2 \pm 12.8$ & $113.9 \pm 14.0$ & -9.888 & $0.000 *$ \\
\hline Fracture to operation time (days) & $3.0 \rrbracket 2.0 \rrbracket 6.0 \rrbracket$ & $3.0 \otimes 2.0 \otimes 6.0 \rrbracket$ & -0.664 & 0.506 \\
\hline ASA classification & & & 1.599 & 0.206 \\
\hline QIIII classification & 67 & 43 & & \\
\hline$\geq$ III classification & 125 & 108 & & \\
\hline Anesthesia method & & & 2.502 & 0.114 \\
\hline General anesthesia & 4 & 9 & & \\
\hline Intravertebral anesthesia & 188 & 142 & & \\
\hline operation duration $\nabla \min \rrbracket$ & $62.7 \pm 17.9$ & $60.8 \pm 17.8$ & -0.998 & 0.319 \\
\hline
\end{tabular}

Page 8/9 


\begin{tabular}{|c|c|c|c|c|}
\hline IBL『m|『 & $190.5 \pm 89.9$ & $231.8 \pm 97.0$ & 4.044 & $0.000 *$ \\
\hline ABT quantity $\llbracket \mathrm{ml} \rrbracket$ & - & $460.9 \pm 237.8$ & & \\
\hline
\end{tabular}

Table 2. Multivariate stepwise logistic regression analysis of ABT after HA in elderly patients with FNF

\begin{tabular}{|c|c|c|c|c|}
\hline Risk factors & OR & $95 \% \mathrm{Cl}$ & Wald Vaule & P Vlaue \\
\hline Age $₫$ Year》 & 1.052 & $1.011-1.095$ & 6.281 & $0.012^{\star}$ \\
\hline $\mathrm{BM} \otimes \mathrm{kg} / \mathrm{m}^{2} \square$ & 0.922 & $0.860-0.988$ & 5.336 & $0.021^{*}$ \\
\hline diabetes & 0.774 & $0.426-1.405$ & 0.710 & 0.399 \\
\hline Preoperative $\mathrm{Hb} \rrbracket \mathrm{g} / \mathrm{L} \rrbracket$ & 0.918 & $0.896-0.940$ & 50.946 & $0.000 *$ \\
\hline IBL囚mI】 & 1.006 & $1.003-1.009$ & 18.496 & $0.000 *$ \\
\hline
\end{tabular}

